\title{
Paradigms in Tourism Research: A Trialogue
}

John Tribe, University of Surrey, UK.

Graham Dann, UiT Arctic University of Norway Alta Campus .

Tazim Jamal, Texas A\&M University, USA.

\begin{abstract}
This article analyses the nature and consequences of paradigms in tourism studies. It is somewhat unconventional in that its co-authors have not sought to produce a synthesised finished product. Rather they have rendered their different perspectives visible through the structuring of the article as a trialogue. It commences with Tribe's thesis that tourism studies is not governed by a restrictive paradigm at the field level but that at a societal level neoliberalism may be viewed as a restricting paradigm. Jamal and Dann then each deepen and extend the analysis of the term paradigm as they engage with the thesis providing sometimes confirmatory and sometimes conflicting analyses. A final round of clarifications and comment concludes the piece.
\end{abstract}

Keywords: Epistemology, Paradigm, Ideology, Kuhn, Tourism Studies

\section{PART A: OVERVIEW}

\section{Introduction}

The study of paradigms reveals that knowledge is rarely settled once and for all. It is nearly always in a process of becoming. By contrast, the publishing of a journal article typically creates a premature consensus, a solidifying of arguments and a closure of related issues. Occasionally, however, an article provokes commentary and that in turn evokes rejoinders. In this way knowledge creation can become more of a dialogue but these situations are quite rare. With such thoughts in mind, this paper revisits the idea of paradigms in tourism research, but also seeks to highlight the provisional status of knowledge production and to incorporate dialogue within it. In fact it wishes to recreate the atmosphere of a good conference where a given topic gets a more thorough debate from a variety of angles. Here difference is encouraged rather than being regarded as something to be determinedly avoided, or solved or worked around in the quest for a neatly polished final solution as is the case in many articles. So it is also different from a normal co-authored article in that the joins, the misunderstandings, the changes in direction are all deliberately left visible. 
This article arose from one of the major conference themes of "Tourism Research Paradigms" at the 2013 tribute to the life and work of Jafar Jafari that was held in Mallorca, Spain. At that colloquium John Tribe presented a keynote address on paradigms while Graham Dann and Tazim Jamal formed part of a closing panel that followed up on various conference themes, one of which was tourism research paradigms. Accordingly, and in order to recreate the dynamics of knowledge disputation and production, this article adopts a dialogical (actually trialogical) approach. It commences with Tribe's thesis. Jamal and Dann then add their analyses of the subject after which a further round of comments and clarifications takes place.

The structure of the article is as follows. In part B, John Tribe examines a number of key areas. First he seeks to more fully unpack the concept of a paradigm. He then applies this and related terms to tourism studies in order to understand the patterns or models used in the field and their knowledge foundations. Next the evolution and current structure of the field is explored and finally Tribe moves from the level of the field to a meta level in order to identify a known but often taken for granted global paradigm and the consequences of this situation for the field of tourism. In part C Tazim Jamal takes up the argument, laying out a brief overview of Kuhn's contributions within the philosophy of science and history of science and translating this to tourism studies. Drawing on Kuhn, she sketches out a macro-micro picture of tourism research, both of which are influenced by Kuhn's "hermeneutic" turn in her portrayal. In Part D Graham Dann examines the notion of paradigm in descending order (paradigm lost) from a general description to its specific uses in the social sciences and tourism research, before arguing that paradigms can only be regained by tackling the issues of linguistic hegemony and ideology. Finally a further round of comments, clarifications and conclusions id offered in parts E-G.

\section{PART B: The Structure of Tourism Evolution (Tribe)}

\section{Paradigms: Definitions and related concepts}

The current edition of the Oxford English Dictionary defines the meaning of the term paradigm as "a typical example or pattern of something; a pattern or model". To this definition Wikipedia adds that the original Greek term (paradeigma) was used to denote the model or pattern that the Demiurge (god), the uncaused cause used to create the cosmos ex nihilo. In more recent times the Research Committee on International Tourism of the International Sociological Association held the first symposium on paradigms in tourism research in Jyväskylä, Finland (July 4-7, 1996). The following year, Dann (1997) filed a report in which he noted the contribution of Marie-Françoise Lanfant who pointed out that: 
"The French usage of the expression "paradigm" derived from a sociolinguistic analysis of discourse by such structuralists as Saussure, Lévi-Strauss, and (the early) Barthes. Their approach, therefore, contrasted with a more ideological vision of the world epitomized by a history of science stance adopted by Anglophone scholars." (p. 472).

Dann subsequently observed that Nelson Graburn stated:

"that etymologically a paradigm in Greek philosophy signified a representation or copy, a patterned device for making comparisons, which much later in the 17th century came to mean a moral exemplar of reality", (p. 472) (i.e., reality as it should be).

Dann himself added that "the $\pi \alpha \rho \alpha$ component indicated that a paradigm went beyond first order reality to the second-order realm of cultural connotation which was emically grounded and captured." (p. 472) That is to say, in anthropological terms, it describes how a group of people think, how they categorize the world, their rules for behaviour and how they explain things, a position similar to that of Kuhn (1962).

There have been various other sightings of the term in the tourism literature and these especially relate to sustainability (Hunter, 1997), (Luo \& Deng, 2008) and discussions about paradigm shifts (Weaver, 2007), (Li \& Petrick, 2008). In fact the expression appears in over fifty recent research article titles - even though it is often used with imprecision. So it is to Kuhn's classic text The Structure of Scientific Revolutions (Kuhn, 1962) that we must turn for a more thorough treatment of paradigms, as Echtner and Jamal (1997) noted in their assessment of the disciplinary dilemmas of tourism studies. Kuhn writes about the word that it:

"stands for the entire constellation of beliefs, values, techniques and so on shared by the members of a given community." (p.175).

Interestingly Kuhn did not consider the concept of a paradigm as appropriate for the social sciences. Rather he explained that the presence of paradigms in the natural sciences offers a key point of distinction from the social sciences where he notes that there are not, nor can there be any such thing. It may be thought that this remark would preclude the need for any sustained analysis of paradigms in tourism research. But there are two reasons why we should persist with an analysis of paradigms. 
First, the term and its meaning as a pattern, or model, or a system of shared beliefs is of use for the social sciences in general and tourism studies in particular. For any mature subject needs to have self-knowledge of both what it is about and how it has come about. And second, Kuhn concludes his book by underscoring "the need for a similar and above all for comparative study of the corresponding communities in other fields ... What is the group collectively seeing as its goals: what deviations individual or collective would it tolerate and how does it control impermissible deviation?” (p.209)

That final remark is surely worth considering because science does have impermissible deviations while in the social sciences there are rarely if ever impermissible deviations i.e. it is more tolerant of pluralism. Social science theories are much less universal, more fuzzy, more speculative and rarely completely settled but rather fluid and on the move. That is surely why Kuhn titled his book the Structure of Scientific Revolutions - because when an existing paradigm gets overwhelmed and overtaken by novel observations and theories the old paradigm is overturned in favour of a new one. In the social sciences the pace is more incremental; hence my choice of "The structure of tourism evolution" as the title for this section.

This offers a good place for Lakatos to enter the argument. In contrast to Kuhn's paradigms, he proposed the model of the 'research programme' (Lakatos, 1975; Lakatos, Worrall, \& Currie, 1978). A research programme consists of a hard core of theory. This represents the basis of the programme so that if it were if abandoned it would necessitate rejection of the whole programme. Surrounding the hard core reside auxiliary hypotheses. These are more modest specific theories that may offer evidence that threatens the 'hard core'. They are akin to areas of incubation and temporary storage areas.

Here I do not wish to get too caught up in outlining the differences between paradigms and research programmes, although the latter will be used later in this paper. The differences are more applicable to science. Rather, to progress things it will be useful to adapt and apply Kuhn's above noted definition of a paradigm to tourism studies as: "the constellation of beliefs values techniques and so on shared by the members of the tourism academy". I might suggest similar terms such as "the canon" or "the tradition", or even "the core". In fact, so as not to get confused with the pure concept of paradigm which I have already established does not translate to the social sciences, the expression "tourism knowledge system" will be used. It will then be 
instructive to understand three key epistemological and sociological questions about that system:

a. How is the tourism knowledge system constructed?

b. What are the dynamics of change in the tourism knowledge system?

c. Paradigms, global structures and processes.

\section{How is the tourism knowledge system constructed?}

Back in 1997 an article of mine appeared in Annals entitled the Indiscipline of Tourism (Tribe, 1997) in which the central focus was on understanding how tourism studies worked, or to use the language of Latour (1999) - to peer inside its black box. The resulting diagram highlighted several important features.

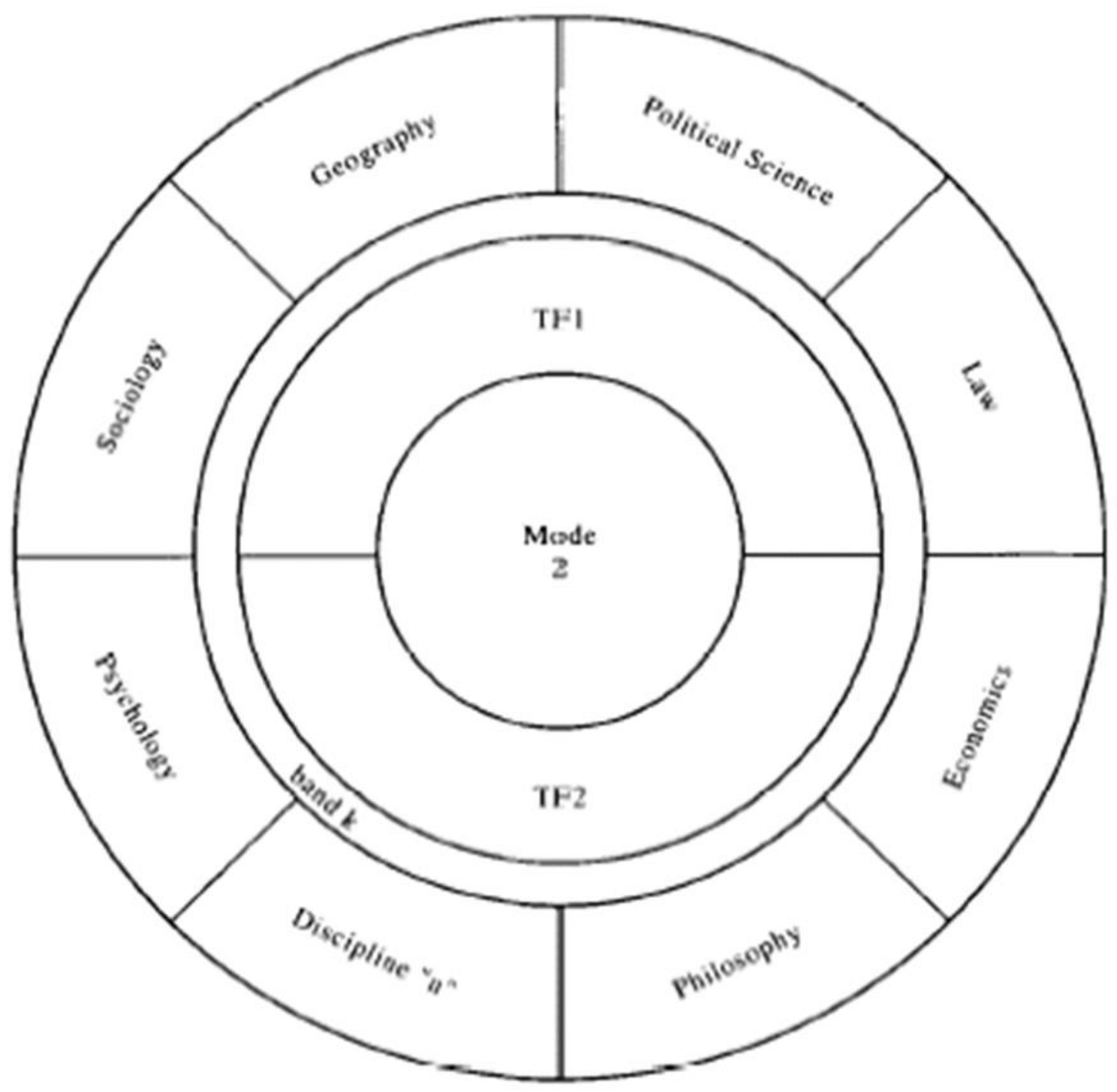

Figure1: Indiscipline of Tourism 
First, it identified the difference between Mode 1 and Mode 2 knowledge. The former is knowledge that is produced in the academy according to its own epistemological rules. The latter is knowledge that "operates within a context of application in that problems are not set within a disciplinary framework ... It is not being institutionalized primarily within university structures..." (Gibbons et al., 1994, p. vii). Second, it demonstrated that tourism did not pass the tests of being a discipline; rather it was better understood as two emerging fields of study (TF1 and TF2). Third, the diagram demonstrated the extent and role of the contributing disciplines and the importance of interdisciplinarity (as argued earlier by Leiper, 1981, as well as Echtner and Jamal, 1997).

Well I have now had 16 years to reflect on this diagram and, after Popper (1959), one might ask whether any falsification evidence has emerged or, in Kuhnian terms, whether sufficient anomalies have arisen to render this view redundant and thereby overturned it in a more revolutionary spirit. The article was subjected to, but survived, an initial onslaught by Neil Leiper (2000) prompting an even more robust account of itself by way of a rejoinder (Tribe, 2000). In broad terms the model still works. Specifically, there has been no evidence produced to falsify the proposition that tourism is a field of study rather than a discipline. So, no revolution, then. Rather some additions are required to assist in the evolution of the model. This relates to the dynamics of the tourism knowledge system which has been addressed by two later contributions.

First, The Truth about Tourism (Tribe, 2006) unveiled what was called the double selectivity of tourism research which, on reflection, might be more accurately described as a triple selectivity. This selectivity occurs when researchers choose what problems to investigate, how to research them and how to report them. It is mediated by the influence of the knowledge force field - person, position, rules, ideology and ends on this process. Paradigms were discussed under the heading of rules where Tribe noted that it is "not possible to present tourism research as operating in the grip of a paradigm" (p. 366), but he did note the softer influence of traditions and discourse.

Second, Tourism Tribes, Territories and Networks (Tribe, 2010) offered an epistemological analysis which focused on the nature and structure of the field, a sociological enquiry which concentrated on the culture and practices of academics in the field and also an understanding 
of actor networks. This article presented the views of academics on a variety of issues including paradigms. The informants rejected the existence of a governing paradigm, pointing instead to tourism studies as a "soft" field of knowledge. Their comments included that it is not too restrictive, that it had emerged in a free form way and that paradigms rather tend to be more present in 'mature' sciences and that tourism is too young to have created any one.

\section{What are the dynamics of change in the tourism knowledge system?}

Having briefly set out the mechanics of the tourism knowledge system we may now turn to what knowledge it has produced. We are all familiar with the establishment of the major conceptual building blocks of tourism by the pioneers of tourism research. For example Dean MacCannell (1976) offered an early insight into tourists' search for authenticity in order to escape the feeling of alienation brought about by the modern configurations of society. Valene Smith's (1977) edited collection examined relationships between Hosts and Guests including Graburn's Tourism: The Sacred Journey framing tourism in terms of personal transformative experience and Dennison Nash's view of Tourism as a form of Imperialism. Erik Cohen's (1974) tourist typology introduced the categories of organised mass tourist, individual mass tourist, explorer and drifter.

If the key foundations of tourism studies were laid down in the 1970's, how have things changed since then? Jafar's (2003) platforms offer some insight into the broad evolutionary

sweeps. He noted that the 1960s phase, - the advocacy platform - was dominated by economists. Next the cautionary platform was identified as having evolved in the 1970s and emphasising the negative as well as positive impacts of tourism, particularly on the environmental front. The adaptancy platform which according to Jafari became popular in the 1980s turned its attention to alternatives to mass tourism. His fourth platform - the knowledge platform - saw tourism as a study of greater maturity, offering a more comprehensive understanding of tourism than the partial earlier platforms. Jafar also tentatively sketched out a fifth platform (2005) - the public outreach platform - which advocated positioning tourism into the world's political structures and better communicating with the broader academy.

Certainly no revolutions can be detected here. Rather the process has been one again of evolution. New theories have been added and old theories have been revised and adapted. In terms of new theories, the so called New Mobilities Paradigm (Hannam, Sheller, \& Urry, 2006) has had an impact, at one stage threatening to engulf tourism in a wider conceptualisation of 
movement. This prompted Hannam to write about the end of tourism in the light of nomadology and the mobilities paradigm (Hannam, 2009). However just as Urry's The Tourist Gaze (1990) was found to be an evolutionary application of Foucault's Le Regard (1980), so one might suggest that Mobilities is similarly an evolutionary application of Actor Network Theory. The Critical Turn (Ateljevic, Pritchard, \& Morgan, 2007) has also gained some momentum perhaps as a reaction to Tourism Studies' lack of political or power consciousness, but it is in essence just a late discovery and application of a decades old movement founded by the Frankfurt School.

Perhaps one of the biggest shifts in tourism thinking has been away from binaries to a much more fluid and messy understanding of their underlying phenomena (Cloke \& Johnston, 2005). Hence Hosts and Guests, Home and Away, Backstage and Frontstage, Authentic and Inauthentic, the Exotic and the Everyday, Work and Leisure have all been critiqued and reworked. Tourism has also been recast from a simplistic demand and supply side analysis to include a better understanding of its performance elements. Urry's temporary influence on the ocularcentrification of tourism similarly has given way to a broader appreciation of the sensuality of tourism and its fully embodied nature (Veijola \& Jokinen, 1994). Meanwhile Paul Cloke (Xiao, Jafari, Cloke, \& Tribe, 2012) and others have sought to break out of the limits of embodiment to consider affect and the ineffable in tourism. The importance of tourism has been underlined by Adrian Franklin's (2004) reference to it as an ordering and Keith Hollinshead's (2009) thesis of tourism as an important force in worldmaking. Tourism is no longer superficial or marginal. Of course research into sustainable tourism has also seen massive increase in effort and activity too. What all this demonstrates is the influence of postmodern thinking on tourism and, perhaps to borrow Bauman's (2000) term, a move towards Liquid Tourism. But yet in this process the business and economics of tourism seems very much to have kept the shape created by its early pioneers.

Finally for a snapshot of which knowledge has become more firmly established as the core of the canon of tourism we may turn to two popular contemporary text books. The first offers an insight into the business of tourism (Fletcher, Fyall, Gilbert, \& Wanhill, 2013) and covers:
a. Tourism Demand
b. The Tourism Destination
c. The Tourism Sector
d. Marketing for Tourism 
The second takes a more social science (Hannam \& Knox, 2010) approach and covers:
a. Regulating Tourism
b. Commodifying Tourism
c. Embodying Tourism
d. Performing Tourism
e. Tourism and the Everyday
f. Tourism and the Other
g. Tourism and the Environment
h. Tourism and the Past
i. Tourism Mobilities

\section{Paradigms, global structures and processes.}

Next I would like to re-invoke the concept of a paradigm to illuminate the workings and influence of global structures and processes, because if we do this we will get something extra out of the term which might help us to understand some of the limitations and frustrations of tourism research in the 20-teens. Earlier I sought to understand the term paradigm alongside similar terms such as canon and tradition before finally settling on "tourism knowledge systems" for the specific study of tourism. Here, I wish to consider the ideology and discourse aspects of the term paradigm. Kuhn's usage only needs a very minor adaptation to read "the constellation of beliefs values techniques and so on shared by the members of society" for it to illustrate a particular point here. And if we now ask the question what is the constellation of beliefs of this paradigm, this ideology, this world view, the answer seems fairly clear.
a. competitiveness
b. deregulation
c. efficiency
d. free markets
e. profit,
f. consumerism
g. capitalism
h. globalisation
i. individualism
j. growth 
The shorthand for these cumulative qualities is Neoliberalism, or sometimes the Washington Consensus. Indeed some of the Tourism Tribes' informants (Tribe, 2010, p. 30) pointed to "the overarching paradigm of neo-liberalism disciplining how the subject operates.” Bem (2013, p. 18) has also underlined this point noting that:

"Tourism has guided its strategies of development and innovation grounded in demands and dynamics located in the market sphere and formed their managers from a pragmatic perspective inspired by classical models of management"

Of course Neoliberalism is not the universal world view - there are substantial national and local pockets of difference. However, the important thing is that this is a highly influential ideology and one which recognises and promotes itself as the natural world view. And if anything this paradigm or ideology has become more deeply entrenched in recent years. Certainly we must concede that other values also get an airing. These include
a. Inclusivity
b. Equity
c. Equality
d. Beauty
e. Sustainability

But what is interesting is that these other values are given space only as far as they do not severely disrupt or upturn the core neoliberal project. Let me now use Lakatos to put these value sets into two domains. Adapting his terms one can identify a neoliberal programme which consists of a hard core of values that represents the everyday working, the well-oiled machine of Neoliberalism. Here the abandonment of any of the elements would threaten the unity of the whole programme. Alongside this hard core reside the other or auxiliary values. These are specific values that may contradict or threaten the 'hard core'. They may cause minor modification to the hard core but are in general subservient to it.

There are two important consequences of this. First tourism research is undertaken within this overarching ideology and generally takes as natural the values implicit in the neoliberal programme. It rarely gives this a second thought. Second tourism itself is mainly driven by the forces of the neoliberal programme and its hard core elements. Referring back to the Greek usage of paradeigma, neoliberalism represents the model or pattern that is used to create the tourism world. Because of this situation, some deep assymetries have continued to grow in tourism as elsewhere. I have previously referred to these as tourism paradoxes. These include: 
a. Poverty Amongst Plenty - where growing asymmetries of wealth and poverty may threaten the global economic stability on which tourism depends

b. Cultural Chasms: Tourism should contribute to cross-cultural understanding; yet we witness regular global cultural clashes. These have the potential to curb the mobility and security that tourism depends upon.

c. The Travel Paradox where mobility is confined to an elite group of mobile travellers leaving a mass of have-nots pressing at the borders of the haves.

d. The Climate/Action Gap: The world is getting hotter but we are still operating high carbon dependent tourism

e. The Generation Gap where an unsustainable gap of wealth and travel opportunity is opening up between the young and the elderly.

f. Beauty and the Beast: Venice demonstrates our human potential for the aesthetic in tourism. But this is so often compromised by deeply unattractive built environments, lacking soul, the human dimension or aesthetic qualities.

g. Human Rights and Wrongs: In 1948 the General Assembly of the United Nations adopted and proclaimed the Universal Declaration of Human Rights; yet human wrongs stubbornly persist

h. Blindness and Apathy: We can of course see most of these problems but we often appear to be blind to them

Moreover any modern large international airport illustrates these paradoxes perfectly. Fast track immigration vs REFUSED visas, First class lounges vs. toilet cleaners. Recycling bins as tokenistic symbols of care engulfed by the totally unsustainable project of mass air travel.

\section{Conclusions: Evolution / Revolution}

In Part B of this article an attempt has been made to understand the nature of paradigms and associated concepts and to apply them not only to the specific domain of tourism research but also to the general ideological conditions of society in which tourism and its research operates. In doing so a number of key points and conclusions may be drawn. The first group of these is about tourism research. First, I argue that there are no paradigms in the strictly Kuhnian sense in tourism research and consequently there are no scientific revolutions in this field of study. For example none of the early building blocks or resultant binaries are banished or declared useless - far from it! Tourism is an open subject area. The absence of a fixed regulatory paradigm means that new work is not excluded. But if there are no paradigms there are discernible discourses, traditions, a tourism knowledge system and a discernible canon. And 
prevailing discourses point to some problematics such as Anglophone-centrism, Westerncentrism, consumer-centrism and the rather limited and uniform horizons of tourism researchers. To summarize, the concept of a paradigm and the tourism knowledge system is useful for the first part of our story since it helps us to understand that the brief history of tourism studies has not been one of tourism revolutions, but rather evolutions.

The second group of conclusions is about tourism in society. The term paradigm does offer important insights here and it has been suggested that Neoliberalism is a kind of paradigm. Here there is a certain incommensurability between the values of the core Neoliberal programme and those human values found in the auxiliary. Let us take as an example the concept of sustainability. The global warming crisis teaches us that we have failed miserably to make progress here because sustainability is subservient to and largely incompatible with the neoliberal programme. So most efforts to confront climate change are abandoned or curtailed because where they conflict with the neoliberal core of growth, individualism, consumerism and so forth, it is the latter that are prioritised over the former. To adapt Kuhn: "[Neoliberalism] ... suppresses [sustainability] novelties because they are necessarily subversive of its basic commitments (p. 5). So here Kuhn's structure of scientific revolutions offers an important insight.

Kuhn wrote that:

"We shall deal repeatedly with the major turning point in scientific development ... Each of them necessitated the community's rejection of one time-honoured scientific theory in favour of another incompatible with it ... And each transformed the scientific imagination in ways that we shall ultimately need to describe as a transformation of the world within which scientific work was done. Such changes together with the controversies that almost always accompany them, are the defining characteristics of scientific revolutions.” (p.6)

He further noted that:

"Political revolutions are inaugurated by a growing sense often restricted to a segment of the political community that existing institutions have ceased adequately to meet the problems posed by an environment that they have in part created"(p.92). 
So bending this back to sustainable tourism we might agree that we are stuck in an epoch characterised by an entrenched paradigm. The epoch in which we are entrenched in is the neoliberal one which does not seem to allow us to achieve a sustainable future in terms of, for example, global warming. This is a paradigm blockage. Perhaps we are at a point of a potential Kuhnian revolution here. Again to quote Kuhn:

"Scientific revolutions are here taken to be those non-cumulative developmental episodes in which an older paradigm is replaced in whole or in part by an incompatible new one" (p.92).

A revolution in this context would take hold where an increasing weight of evidence demonstrated the inability of neoliberalism to solve the pressing problems of global warming. Kuhn talks of the key moment when:

"an existing paradigm has ceased to function adequately in the exploration of an aspect of nature to which that paradigm itself had previously led the way" (p.92).

Such a paradigm shift would need to see an increasing abandonment of neoliberalism by its adherents. As Kuhn noted, for scientific revolutions a new paradigm needs "to attract an enduring group of adherents away from competing modes of scientific activity." (p.10). This paradigm shift would occur when, say, sustainability became the winning social programme with sustainable values and principles at its core. Neoliberal values would be downgraded to occupy the position of the auxiliary: They would be useful to be taken account of but always overridden by the needs for sustainability. But it is still necessary to say that the neoliberal programme seems to be very firmly entrenched and it will be interesting to see whether it survives the very real challenges to human futures ahead of it. To summarise - the concept of a paradigm is central to the second part of our story in helping us to understand the structure and course of the development of tourism as shaped by the forces of the wider world and the incommensurability of the paradigms of Neoliberalism and Sustainability

So, by way of a final conclusion to part $\mathrm{B}$, it is suggested that tourism research is progressing by incremental evolution including theories of pro-poor tourism and sustainable tourism. However an ideological paradigm shift is needed to achieve real headway in, say, just tourism or sustainable tourism since progress is at present effectively suffocated by the hegemonic nature of the prevailing and deeply entrenched neoliberal paradigm.

\section{PART C: A Kuhnian perspective on Tourism Studies as a "disciplinary matrix" and paradigms as exemplars (Jamal)}


The philosophy of science and the history of science, two different but vitally important tracts, have greatly influenced the evolution of thinking and epistemological debates in the social sciences. Given the importance of science's influence on positivistically oriented, quantitative research in tourism studies, a closer look at some of the debates and issues on the nature of science and scientific progress is merited in order to understand their impact and influence on tourism research. The main focus of this section is the contribution made by Thomas Samuel Kuhn (1922-1996), a historian of science and one of the most influential philosophers of science of the twentieth century. The Structure of Scientific Revolutions is one of the most cited academic books of all time and, according to Kuhn, first aroused interest among social scientists, and subsequently among the philosophers that he intended to address, followed by a wider academic and general audience (Bird, 2013). His discussion on paradigms and how they operated in scientific communities recast the history of science as a "succession of a priori assumptions guiding historically limited communities of scientists" and influenced extensive epistemological debate and arguments in the social sciences (Turner and Roth, 2003: 8).

Noting the rapid impact of his work on the sociology of knowledge and the confusion over his use of the term "paradigm", Kuhn subsequently clarified this concept, using a "disciplinary matrix" when referring to paradigms in the larger sense, and "exemplars" to illustrate paradigms operating within this larger matrix. As he stated in his 1969 postscript in Kuhn (1996), a paradigm in the larger sense governs a group of practitioners, a "disciplinary matrix" consisting of a group of scholars, an entire culture with possibly sub-communities within it, engaged in activities characteristic of an immature or mature science. Kuhn (1996) describes an immature science, in what he sometimes calls its 'pre-paradigm' period, as lacking consensus. Competing schools of thought possess differing procedures, theories, and metaphysical presuppositions, and a great deal of intellectual energy is put into arguing over the fundamentals with other schools instead of developing a research tradition (Bird, 2013). However, one school may make a breakthrough — thereby progressing the field and advancing the potential for paradigm development (see Echtner and Jamal, 1997, for more on this issue). The consensus of a disciplinary matrix is primarily agreement on paradigms (i.e., exemplars) operating within the matrix.

\section{Paradigms (exemplars) within the "disciplinary matrix" of tourism studies}

In a Kuhnian sense, tourism studies in the sixties and seventies can be seen as an emerging "disciplinary matrix" where tourism was the focus of academic investigation by participants 
from various disciplinary orientations and fields of study, and where industry and economic interests established a strong dominant foothold (Franklin and Crang, 2001). Postpositivism in the social sciences and tourism studies became entrenched as an 'exemplar' (paradigm in a narrow sense) that progressed through 'normal science' until anomalies built up and conflicts arose. Consider, for example, the qualitative-quantitative debates, and postmodern and critical intrusions from other social science and humanities domains in the 1980s and 1990s - these have enabled new methodological paradigms (e.g., constructivism, phenomenology and critical theory) to arise (see Denzin and Lincoln, 2005; Jamal and Hollinshead, 2001). In Kuhnian terms, it could be argued that resistance to replacing the entrenched (post)positivistic paradigm by qualitative and critical methodologies has been overturned, allowing alternative methodological and theoretical paradigms to emerge and coalesce alongside the scienceinfluenced dominant (post)positivistic paradigms Some might even see this as a scientific revolution, where all forms of social research (even postpositivistic hyothetico-deductive pursuits) are considered to be socially constructed, interpretive endeavours (see Jamal and Everett, 2004).

Kuhn argued that science progressed through "puzzle solving activities" during periods of normal science, punctuated by "extraordinary science" when a growing array of anomalies and rival paradigms (exemplars) eventually result in a crisis due to incompatibility and incommensurability, and a scientific revolution brings forth a new paradigm (exemplar). Among the examples of exemplars Kuhn cites are Aristotle's analysis of motion, Ptolemy's computations of planetary positions, Lavoisier's application of the balance, and Maxwell's mathematization of the electromagnetic field as paradigms (Bird, 2013). In the young "disciplinary matrix" of tourism studies, for instance, a range of exemplars (paradigms) are currently vying for visibility and form. In addition to the methodological paradigms mentioned above are theoretical paradigms that are often introduced from other social science areas (e.g., neocolonialism, dependency and core-periphery theories from geography, 'alternative development' approaches from development studies, etc.). The shift away from binaries to more fluid and messy understandings of tourism phenomena, aided by the performative and critical turn in tourism, is also inspiring new concepts like 'worldmaking' (Hollinshead, 2009), as well as embodiment critiques that are enabling the "I" to be written in tourism journal articles (Swain, 2004), and new excavations of traditional policy domains, e.g., destination governance under mobilities (Dredge and Jamal, 2013). The battle between neoliberalism and sustainable tourism that Tribe outlines above, can be viewed here as different exemplars or sub-community 
activities within the broader "disciplinary matrix" of tourism studies. Note too that Kuhn referred to scientific revolutions at the level of exemplars (paradigms in the narrow sense), not to the broad disciplinary matrix, which is what Tribe appears to be referring to when he says "no revolution" (in the tourism knowledge system) above.

\section{Incommensurability and the theory dependence of observations}

Numerous debates raging in the $20^{\text {th }}$ century on the philosophy of science and the work of philosophers of science like Karl Popper served to stimulate and influence Kuhn's treatise. Popper's doctrine of falsificationism served to establish the importance of the hypotheticodeductive model in the philosophy of science (the same model being used by quantitative researchers in tourism), and transformed the debate on science and the scientific method. Popper claimed that the logical method of the sciences was falsificationism and, furthermore, that science progresses through trial and error, where truth was arrived at through the scientific theories being subject to criticism and testing. This model informs the postpositivistic paradigm in which quantitative survey methods are based. Kuhn, however, launched two highly influential 'revolutions' that challenged the received views of science then, both in terms of the validation of scientific knowledge and also how science progressed. In the philosophy of science, the rules and standards governing scientific endeavours were considered inviolable in establishing the legitimacy of scientific theories. Kuhn established clearly the theory dependence of observations, which created an immense challenge to both Popper's falsificationism and Lakatos' research programmes (see pp. 159-163 in Kourany (1998) for an excellent summary of Kuhn's critique of theory choice). Lakatos had attempted to build the inviolable "core" of his "research programme" by adapting Popper's falsificationism. But as Hughes and Sharrock (1997: 82) explained: "Facts, methods and standards are internal to paradigms and there is no independent position from which to judge them - least of all by an appeal to a world independent of any theoretical positions whatsoever."

Kuhn's critique of theory assessment and how science progressed offers a significant challenge to Lakatos's portrayal of science as progressing through research "programmes". For Lakatos, progressive theories tended to exist (rationally) alongside less robust or even disconfirmed theories until the research programme had matured, but this applies to a mature science only! "My account implies a new criterion of demarcation between 'mature science', consisting of research programmes, and 'immature science' consisting of a mere patched up pattern of trial and error", says Lakatos, who then goes on to criticize "weak programmes...like Marxism or 
Freudism" (Lakatos, 1970). Kuhn turned to the history of science to show that science was a sociological institution where newcomers are socialized into a received frame of reference, learning how to work and think within the parameters established within that particular paradigm. As Bernstein (1983) explained, one of Kuhn's main motivations in introducing the slippery term paradigm was to convey the primary sense of a "concrete exemplar that is open to differing interpretations" (p. 57). Incommensurability between scientific theories could not be accounted for by relying on scientific rules and standards, and evidence that may appear to falsify a theory may turn out to be accounted for by adjusting the paradigm (using different values and viewpoints) rather than abandoning it (Bernstein, 1983). Hence, the dominant paradigm is not necessarily abandoned at the first sign of anomaly and those who disagree with the paradigm shift, can continue to dispute it. Such is the state of tourism studies, where entrenched postpositivistic interests can continue to challenge the legitimacy of diverse interpretive paradigms and the emergence of a range of critical, praxis oriented tourism scholars" (Jamal and Everett, 2004).

\section{Hermeneutics and "progress" in Tourism Studies}

Despite their differences, Popper, Kuhn and Lakatos were strongly concerned to confirm the inviolable value of rationality in the sciences, which was being strongly debated by key figures such as Feyerabend in Against Method (1975) and Peter Winch in The Idea of a Social Science (1990). While Kuhn had criticized models of science that progressed on a continuous, linear scale, he believed that science did progress and scientific knowledge did grow, but it did so through more than a rational accumulation of knowledge - and far more than rationality is at play when claims to knowledge are being made or evaluated. The core of Kuhn's incommensurability thesis, as Bernstein (1983: 108) pointed out "is not closure and being encapsulated in self-containing frameworks but the openness of experience, language, and understanding." And this hermeneutic endeavour took places within communities of scientists. Jafari's (2005) much-cited platforms, a proliferation of tourism-related journals and conferences and theory building efforts occurring within satellites or nodes of small communities of tourism researchers worldwide are similarly illustrative of "progress" in the relatively new domain of tourism studies. The critical tourism studies conference that was first held in Croatia in 2006 has seen subsequent iterations attended by a growing base of critically oriented communities of scholars and researchers from such diverse social science areas as Geography, Anthropology, Sociology, Economics, Political Science, as well as humanities oriented areas such as Women and Gender Studies, Postcolonial and Cultural Studies, etc. 
Intense debates and new challenges to knowledge production (e.g., 'standpoint epistemologies' and phallogocentric critiques of knowledge productions, see Harding, 2003) and to tourism education (see, for example, gender activism in the TEFI8 (Sheldon et al. 2011) conference in Guelph, Canada, June 2014) are being launched. Of especial importance within the "disciplinary matrix" are new fissures establishing new sub-communities and research paradigms through the emergence of the "other"- indigenous and native scholars from the developed world and from the global "South who are contesting Eurocentric knowledge production and research practices (e.g., decolonizing methodologies, see Smith, 1999).

These above examples are illustrative of "progress" in a young field of 'Tourism Studies' that is still arguably in the "immature", "pre-paradigm" phase. Qualitative journals, conferences, and a robust community of scholars in qualitative research are proliferating, and qualitative research courses are making inroads in social science curricula (including tourism studies). As Kuhn pointed out for the physical sciences, the development of specialized journals, the foundation of specialist societies, and the claim for a special place in the curriculum, were indicative of a group's first reception of a single paradigm. In this sense, the emerging field of tourism studies is making progress, in both the larger sense of "disciplinary matrix" and the narrow sense of paradigms as exemplars (glimmers of which can sometimes be seen among Dann's different understanding and elaboration of a 'paradigm' below). Unlike Tribe's stance above, my analysis situates a Kuhnian assessment of a young "disciplinary matrix" and an "immature" field (in Kuhn's sense of the term) - how it progresses in terms of the history and philosophy of tourism studies is a story in the making.

\section{PART D DANN: "Paradigms Lost or Paradigms Regained?"}

Part D offers a dialogic critique of certain points made by Tribe in part B under five headings:
a. Issues of etymology and definition
b. Paradigms in the social sciences
c. Paradigms in tourism research
d. Anglocentrism in tourism studies
e. Ideology and paradigms: vive la difference

\section{Issues of Etymology and Definition}

Following its etymological derivation ( $\pi \alpha \rho \alpha$ - beyond, $\delta \varepsilon \imath \kappa v v ́ \mu i ́$ - show) and insights supplied by a number of commentators, Dann's paper originally presented to the 1996 Jyväskylä 
symposium, and subsequently revised for a different audience (2011a), defines a social scientific paradigm as: "a multi-theoretical, open-ended conceptual framework, which goes beyond sensate reality to the realm of connoted meaning, in order to provide a partial interpretive understanding of that reality" (2011a: 23-24)

From this definition it should be noted that:

- Whereas some commentators give the impression that paradigms and theories are synonymous (e.g., Ritzer, 1975), the position adopted here is that, more often than not, any given theory is a subset of a paradigm, i.e., two or more compatible theories constitute a paradigm. Thus the use of such labels as "critical" and "constructivist" to designate in tourism studies a single theory can be misleading, to the extent that "critical theory" and "constructivism" are themselves multi-theoretical, and hence paradigmatic.

- Theoretical pluralism often implies multi-disciplinarity, particularly where boundaries between the social sciences and humanities are becoming increasingly blurred (Denzin, 1989: 46; Smart, 1994: 150). This section thus shares with Tribe the conviction that there is little room for post-disciplinarity in social scientific fields such as tourism studies.

- Paradigms are theoretical starting points (termini a quo), rather than endpoints (termini ad quет). In order for knowledge to progress, paradigms are necessarily open-ended (Denzin, 1989: 36). They die in order to be born again; they are lost in order to be regained.

- Since paradigms go beyond first order sensate reality (c.f., Positivism, Behaviourism) to second order meaning (motivation), interpretive understanding (Verstehen) of that meaning is necessarily emic in nature. However, in order to be generalizable, participant theory should be viewed in its typicality, rather than in its idiosyncrasy - in its form, rather than in its content.

- Nevertheless, interpretive understanding is never complete understanding. Philosophically speaking, the truth it provides is always relative, i.e., constructed by those defining given situations as real (as in Symbolic Interactionism). Paradigms thus offer less than revealed belief systems (Guba, 1990: 9, 17). They are not metaphysical worldviews grounded in essences or absolutes; rather they are conceptual frameworks based on shifting meanings in changing space and time. The trajectory moves from meaning based on essence to meaning grounded in existence, from paradigm lost to paradigm regained.

As regards certain paradigmatic issues, the foregoing definition responds in the following Guba created (1990:10-11) categories of accommodation, knowledge accumulation and 
values. (Guba, it should be noted was the first scholar to initiate The Paradigm Dialog with specific reference to the social sciences).

- Accommodation: As previously seen, in order to be included in the same paradigm, theories must be compatible, if not in ideological terms then at least in general aim. Thus a shared goal of understanding at the level of meaning would render intra-paradigmatic theories compatible, whereas the inclusion of first order and second order theories within the identical framework would violate this minimum criterion. As a corollary, even rival interpretive theories can be accommodated in the same paradigm provided they can achieve synthesis through dialectical exchange. Less clear is the case where one theory attempts causal explanation while another essays interpretive understanding, since it is debatable whether or not the former exists on the same methodological continuum as the latter.

- Knowledge Accumulation: The notions of interpretive understanding and relative truth necessarily imply that no one theory or paradigm has all the answers. Within a given paradigm, however, several theories can synthetically and epistemologically combine towards a higher level of knowledge construction than would be obtained from the input of a single theory. Furthermore, the open-endedness of the paradigm itself, and hence the possibility of "paradigm shift" (Kuhn, 1962), is conducive to greater knowledge accumulation. More debatable is the question of whether cumulative knowledge is simply the summation of all forms of empirical research or whether it should instead be generalizable knowledge that transcends temporal and spatial considerations, i.e., perennial à la Simmel.

- Values: The classical Weberian distinction between "value freedom" and "value commitment" applies not so much to choice of research topic as to the research act itself. Those who argue that research should be conducted objectively and neutrally (PostPositivist paradigm) are patently at conceptual loggerheads with those who regard both the investigator and the investigated in terms of trans-subjectivity (Constructivist paradigm) jointly engaged in a programme of ameliorative social action (Critical paradigm). The domain of values is therefore another instance where paradigms may differ with respect to general aim, and consequently have insufficient grounds for accommodation.

Also worthy of note is the realisation that the definition of a paradigm offered here concurs with Ford's ((1975: 12) contention that, 'all thought whether in everyday life, in science or in any other realm, is paradigmatic, that is to say, all thought is patterned on some mould.' It 
further agrees with her that paradigms comprise basic beliefs, figurations of facts, rules of reasonableness and kept knowledge (Ford, 1975: 16-26), and that paradigms can be "broken out of", shifted or transcended through "sociological imagination" (Ford, 1975: 73-75; c.f., Denzin, 1989: 4; Kuhn, 1962: 122-123; Mills, 1959; Popper, 1963: 56).

\section{Paradigms in the Social Sciences}

Earlier under Values, we saw that Guba (1990) claimed that there are three basic paradigmatic approaches in the social sciences: Post-Positivist, Constructivist and Critical (to which he later added the category "Participatory") Since they are based on quite different sets of values such "master" paradigms are contrary, if not contradictory, in outlook to one another, and hence ideologically distinct. A far different view is held by Kuhn (1962) who, in trying to justify the theories and methods of the natural sciences, finds himself denying the existence of paradigms in the social sciences for reasons of inappropriateness (see Tribe earlier). Even the presence of positivism in both the natural and social sciences (the latter under the influence of the father of sociology, arch-positivist, Auguste Comte) appears to constitute insufficient grounds for him to change his mind.

However, according to Lyotard, such a modernist position based on scientism is quite untenable in a postmodern era. In the words of sociological theorist, Norman Denzin (1986: 198), 'The vision of a noise-free fully communicative social order based on rationality and consensus is rejected by Lyotard.' Denzin continues by stating that the present post-modern 'media society, a society of the spectacle...has created a crisis in the legitimation of science, technology and society. The grand narrative legitimating structures of the past turned on two myths: the belief that science could liberate humanity (the French Revolution), and the belief that there is a unity to all knowledge, producing cumulative rational understandings of man, nature and society' (German idealism) (Denzin 1986: 198-199). There are thus, according to Lyotard (1984) two types of knowledge: narrative and scientific. The former which is not purely objective and denotative depends on rules of competency that are promissory, performative and prescriptive; the latter relies solely upon denotative rules. The former corresponds to the taken-for-granted knowledge structures employed in everyday life by ordinary people; it is thus regarded (by élitist natural scientists) as inferior to scientific knowledge (Denzin 1986: 199-200). Were Kuhn to engage in an ego-centric reductio ad absurdum, he might say that for such a situation to change there would have to be a major paradigm shift, so fundamental in fact that it could 
signal the actual demise of the natural sciences themselves. Here, words such as "hoisted", "own" and "petard" come to mind.

\section{Paradigms in Tourism Research}

Relating the foregoing to tourism, Cohen (1979: 31) captures the essence of the above definition of a paradigm when he observes:

'The complexity and heterogeneity of the field of tourism suggests that there is no point in searching for the theoretical approach to the study of tourism, just as there is no point in searching for the conceptualization of the tourist. Rather a pluralistic and even eclectic research strategy is advocated' (emphases added).

In other words, theory-driven tourism research should draw on a variety of compatible theoretical offerings, in such a way that their cumulative insights can be brought to bear in an analogous fashion to a jigsaw, on what is "sociologically problematic" (Dann and Cohen, 1991: 157, 161). This "kaleidoscope" of understanding is yielded by selectively abstracting the most useful content from a number of accommodatable theories, while abandoning the conceptually barren.

Thus, for example, tourist motivation, (which is sufficiently problematic as to constitute the core of understanding the phenomenon of tourism), can be usefully explored by initially borrowing ideas from Weber and Schutz. These far from comprehensive insights can be subsequently developed by introducing the allied theoretical concepts of "alienation" (Marx, Habermas, Simmel), "commoditized play" (Baudrillard, post-modernism), "the quest for the sacred" (Durkheim, Éliade, Turner), and so on. One begins with an individual or combined approach (e.g., social action theory and/or phenomenology), and then enriches by adding appropriate offerings drawn from within and without that perspective.

At this juncture it is necessary to reinforce once more the distinction between a natural science and a social science approach to tourism theory, the former leading to an unjustifiable science of tourism known as "tourismology" (as outlined by Jovičić (1972) and critiqued by Dann and Liebman Parrinello (2009)). Yet both approaches have their corresponding methodological counterparts in (neo) positivism (quantitative) and interpretivism (qualitative). Here, like Jamal and Hollinshead (2001), Pernecky (forthcoming) points out: 'Under the premise of qualitative inquiry, the notion of "alternative paradigms" emerges as a response to positivist/post-positivist approaches to research, and gives rise to new research paradigms such as 
constructionism/constructivism, interpretivism, critical theory, and the transformative paradigm. Mainly inspired by scholars advancing qualitative research, efforts have been made to delineate the differences between various paradigms. However, the attempt to organize paradigms into neat categories can be problematic, as has been shown in relation to Tourism Studies by Pernecky (2012)'.

Pernecky (forthcoming) elaborates his position by pointing out (in agreement with the positions of Tribe, Dann and Jamal) that in Tourism Studies, 'different disciplinary foci allow for new paradigms to emerge at a disciplinary level (for example: Psychology: imagery paradigm, Sociology: symbolic interaction, Anthropology: instrumentalism, Cognitive Science: enaction, etc.). Although most tourism research draws on paradigms grounded in qualitative research, Tourism Studies is showing signs of maturity by engaging in novel conceptualizations and understandings of what tourism is and does. Here there are currently two leaders in the field of tourism: Worldmaking which speaks of the transformative power of tourism and its ability to re-make and de-make worlds (Hollinshead, Ateljevic and Ali 2009), and the Mobilities Paradigm that seeks to understand tourism in terms of the movements of objects and things, but also relationships, meanings and performances (Urry 2000). These new theoretical perspectives are promising, for they have the ability to advance the knowledge of tourism beyond conventional wisdom. Tribe (earlier) cites these two new paradigms and so largely concurs with Pernecky.

However, there are other paradigms in Tourism Studies which exist without being mentioned in the same endorsing breath. Here one egoistically thinks of "the language of tourism" paradigm (Dann, 1996, 2011a) which is also qualitatively based. More to the point, however, it is multitheoretical in the sense that it examines tourism as a form of social control, while at the same time entertaining the notion of "the tourist as child". Additionally it has been autocritiqued and reformulated (Dann, 2012) largely on account of new digital media of tourism communication with all that these imply in terms of dialogue and trialogue between the tourist industry, tourists and tourees. The challenge therefore would appear to lie in the discovery of paradigms that represent similar shifts in thinking. For an update on the situation of paradigmatic thinking in tourism it is interesting to note that in November 2011 the University of Tromsø held a seminar dedicated to "Paradigms in Tourism Theory" (see Dann, 2011b and his critique of Aramberri (2010)) 


\section{Anglocentrism in Tourism Studies}

Tribe, when earlier acknowledging that there was an Anglophone bias in tourism theory (and hence in paradigms circulating in tourism studies) appeared to reinforce the situation of English speaking hegemony from the various theoreticians that were selected as examples of enlightened understanding of various aspects of the tourism phenomenon and (incorrectly) accorded by him the status of "pioneers". In other words, while he justifiably quoted such commentators as authorities in the field he did not seem to relish the idea of exploring their European predecessors whose original insights predated those of the Anglophone scribes by some 30 or 40 years, many of whom covered the same theoretical ground. So why was this the case? Was it simply a question of overlooking what had gone on before elsewhere, or of being unable or unwilling to understand what was being said in another unfamiliar tongue or (perish the thought) of engineering a paradigm shift from mainly French and German concepts to those of an Anglophone formulation and persuasion)? From where did MacCannell derive his ideas on alienation, for example, or Graburn the fundamentals of a sacred journey, or Cohen on strangerhood? The list goes on and on. True, there was a passing mention of Marie-Françoise Lanfant's contribution to the first seminar on paradigms in tourism research and how the French way of thinking was so different from the Anglo-Saxon variety, but surely that should have been the rule rather than the exception. Although this is a topic that has received a lengthy treatment by Dann and Liebman Parrinello (2009), alas there has been very little feedback or conversion in attitude from those who, though in some exceptional cases are multilingual (e.g., Cohen), nevertheless choose to write predominantly in English. Naturally this raises the question of whether this is a form of intellectual amnesia? If the answer is in the affirmative, then what are the implications for paradigms in tourism studies? Maybe the much vaunted "paradigm shift" should first involve a sociolinguistic change in patterns of communication rather than a xenophobic air-brushing of history.

\section{Ideology and Paradigms: More of the Same or Vive la Différence?}

Tribe suggested that paradigms and ideologies were similar if not identical, to the extent that the terms were more or less interchangeable. We also saw that Guba's master paradigms of positivism, post-positivism, critical theory, constructivism and participatory/cooperative paradigms were spoken of in ideological terms as having their own approaches and hence political agenda. Moreover, Kuhn's "scientism" was said to be at odds with postmodernity to the extent that it was described as an "ism", i.e., an ideology. Jafari's platforms that were introduced consecutively over the years were also said to have multiple ideological bases. And 
finally, Tribe argued that the paradigm of neo-liberalism was opposed to the paradigm of sustainability for ideological reasons. In other words, their natural world views contradicted one another.

However, Marie-Françoise Lanfant (2005) argues that ideologies, i.e., "doctrines which rest on dubious or false theories... have a credibility that they do not merit" since they are based on idea systems that are the expression of certain vested interests, e.g., "so-called scientific objectivity and value freedom". No small wonder, she maintains, that "ideology as an operational category" has given rise to "many works in the sociology of tourism (particularly in France and Germany)". Of course such treatises in their original languages and long-awaited translations would remain largely unknown in the Anglophone world and, as a result, ensuing original critique and dialogical progress would be virtually absent.

\section{PART E: Reply by Tribe}

Well, how fascinating, how enriching, and how to respond to Jamal and Dann? Actually I think there are not many major points where I would disagree with either but rather each has provided a deeper and more refined exploration of paradigms and opened up slightly different lines of enquiry. I think that the root of any possible disagreement lies within the way each of us uses the term paradigm and what we choose to do with the term. Like Kuhn, between us we have used the term in many ways. I will fully admit to using the term rather loosely, more as a jumping off point to enable me to make two very broad points.

I should reiterate that the broad question I wished to address (which on reflection I did not make sufficiently clear in part B) is actually inspired by Foucault and is roughly "are there any limits to what is sayable in tourism research?" (is there a restrictive paradigm?). I address this issue on two macro levels. First by examining any internal limiters - i.e. is there anything within the field of tourism studies that limits what is sayable? Second by examining any external limiters - i.e. is there anything outside of the field of tourism studies that limits what is sayable? And I deploy two major aspects of the term paradigm here. One: Kuhn's explanation of the term as "the entire constellation of beliefs, values, techniques and so on shared by the members of a given community." Two: the definition that refers to "a pattern or a model". Now this is where I think Jamal, Dann and I part company. I search for the pattern, the model the community, the constellation. Applying this to the level of the whole field of tourism I find no exclusive pattern or model that limits what is sayable. (This level of analysis would 
coterminous with Kuhn's terminology of a "disciplinary matrix" that Jamal has unearthed). (But I don't like Kuhn's term as the field of tourism is not limited to disciplinary knowledge and includes extra disciplinary knowledge as well). So no overall all-encompassing paradigm. So no need for knowledge revolutions in tourism. There is nothing that has to be cast aside that is blocking the emergence of "new knowledge". (The easy emergence of "The Critical Turn" is a good example of this). Different tourism knowledges sit side by side quite easily. Hence my story is of The Structure of Tourism Evolution rather than Revolution. I think Dann offers good evidence to support this evolutionary view as he traces the development of, for example, tourist motivation. I also think he endorses my view of pluralism in tourism studies in his citing of Cohen's similar view. Dann's use of Guba's Paradigm Dialog further analyses the extent to which such pluralism is possible.

However Jamal and Dann each using a more refined analysis than mine search for and find multiple paradigms (or "exemplars" in Jamal's classification) both at a theoretical and methodological level. I agree. Where I differ is the extent to which Jamal implies the existence of paradigm wars. For there is no need, for example, for any methodological paradigm to seek to win such a war. Methodological paradigms are simply a case of having different tools to approach different research problems. They can co-exist. They are not mutually exclusive. Moving on, I do not concur with Jamal's view of tourism studies as an immature subject. It is well established in terms of numbers of professors, academics, students, PhDs, journals and has infiltrated traditional academic structures (e.g. recognition as a discrete research area by the UK government in its national research evaluation exercise).

Returning to my second broad question I do find there are limits to what is sayable at the societal level and again I rather permissively use the term paradigm as a way to gather together thoughts, ideas and power issues to assert that neoliberalism is a kind of a paradigm (I am not totally clear if Dann supports this move) and to further use Kuhn's ideas to assert that it is incommensurable with other competing paradigms of say sustainability or quality of life, or ethical development and that this explains why so many of the larger challenges in the nexus of tourism and society remained unresolved. To clarify my thinking further here, Jamal interprets this battle between neoliberalism and sustainability as one of "different exemplars or ... within the broader "disciplinary matrix" of tourism studies". But what I am actually saying is that this is a paradigm war that exists at a level higher than that disciplines or fields of study such as tourism. It is occurring at a general societal level. 
Finally Dann takes me to task about Anglocentrism in tourism. Indeed rather more strongly he points to a xenophobic air-brushing of history. Other than this latter point I am in entire agreement with his discussion on this subject. All I would add is this. From a god-eye perspective there are no centrisms. There is only what exists - various language, cultural, regional and national stories of tourism. But from a pragmatic point of view there is no doubt that English is the lingua franca of tourism. It is this dominance of the English language that air-brushes other accounts out of the way and renders them less visible, not me!

\section{PART F: Reply and Conclusions by Jamal}

The dialogue between the three co-authors could without too much difficulty be viewed in terms of thesis, anti-thesis (Jamal), anti-thesis (Dann) and synthesis (see Dann's comment below). After all, there are synergies between my elucidation and those of Tribe, who draws inspiration from Kuhn to create "tourism knowledge systems." Tribe speaks of the evolution of the field of tourism studies, Kuhn concurs with "progress" of scientific knowledge. Both Tribe and Dann are in accord with the interpretive turn in tourism research, even though they do not see it as a "revolution" in Kuhnian terms. Similar to Kuhn view of science, both recognize tourism and social research as a value-laden endeavour (see Tribe's discussion on selectivity, tradition, and discourse, and Dann's on Verstehen and Weber's distinction between "value freedom" and "value choice"). Tribe's "tourism knowledge system" is not dissimilar to Kuhn's distinction of "disciplinary matrix" in terms of scale or the sociology of knowledge (consider, for example, communities of scientists and the politics of knowledge production). But he departs from Kuhn when at the micro-level he depends on Lakatos's research programmes (rather than paradigms), and also when he introduces neoliberalism as an overarching "paradigm war" (his words) at an entirely different (societal) scale.

Dann sticks with the term paradigm, but while his discussion of "multi-theoretical paradigms" differs from Kuhn's micro-level situating of paradigms as exemplar, his argument for theoretical pluralism may find surprising resonance in Kuhn's post-1962 clarifications of the term paradigm (see postscript in Kuhn, 1996, for instance). From a tourism studies perspective, within the Kuhnian "disciplinary matrix" are communities of scientists (groups and subgroups) engaged with various problem domains (e.g., tourist motivation, tourism mobilities, gender and sexism, visitor experience, sustainability); within these might be found a range of methodological and theoretical paradigms, competing paradigms and possibly even rejected 
paradigms that can continue to operate even after a paradigm shift has occurred. The interpretive and postpositivistic paradigms co-exist, indeed, but are now tackling new legitimation crises such as are related to postcolonial, praxis-oriented, activist research, and gendered domination in academic practices (see Ateljevic et al, 2007).

Myths and misunderstandings of Kuhn abound, inhibiting potential synthesis. Accusations of scientism in Kuhn might tend to soften with greater familiarity of Kuhn's critique of the philosophy of science - the theory dependence of observation and his discussion of incommensurability, for instance, paved the way for understanding science as a hermeneutic endeavour (Bernstein, 1983). Kuhn was very much aware of the hermeneutical impact of his 1962 book (The Structure of Scientific Revolutions) on the social sciences and the sociology of knowledge and it would be unfair to lock his earlier understandings into a static and locked position on the relevance of paradigms to the social sciences - early Kuhn and late Kuhn are jointly integral to evaluate the merit of his work to tourism studies (see Kuhn, 1996; also see Bird, 2013). Lest this all appears to be a theoretical mumbo-jumbo, the stakes are high as I argued in Mallorca last October at the "Celebrating and Enhancing the Knowledge-Based Platform: A Tribute to Jafar Jafari" conference. The unfolding of this young field and its "disciplinary matrix" has immense implications for tourism education and curricula, tourism planning and policy making, and the development of an inclusive, diverse, gendered 'knowledge base platform'. It will take more than the jug of wine, loaf of bread, and Omar Khayyam (poetical evocation by Dr. Jafar Jafari at the Mallorca conference) to arrive at a synthesis but collaboration, informed dialogue, and timely debates like the one we undertake here, are a start.

\section{PART G: Reply and Conclusions by Dann}

Having come to the end of this necessarily lengthy exercise, Tribe, in part E, usefully highlights points of agreement and difference between himself and his two co-authors. Had there just been total consensus among all three parties to the encounter then the benefits of debate would have been lost. Jamal (in section F, above) deals with the confrontation between her points of view and those of Tribe. In this section G, I similarly limit myself to variation in opinion.

The first point of dissent which emerges indirectly from Tribe's discussion of limits and extradisciplinary knowledge when contrasted with my own position is the whole (largely unexamined) question of what constitutes a paradigm in terms of original thought (see 
Aramberri 2010). Here Tribe appears to support the laissez-faire view that anything goes as long as there is freedom from internal and external constraint. Thus, for example, we could have a paradigm of authenticity just as we could entertain a paradigm of sustainability. However, crucially the former is grounded in the social sciences while the latter is decidedly not. How then can they be treated as equal when their rules of intellectual rigour are so different? Perhaps this is an instance of where Tribe could benefit from his own much cited distinction between disciplinary knowledge and (best business) practice (Tribe 1997), the difference between tourism theory in such social scientific disciplines as anthropology and sociology, etc. and the second hand borrowed theory by the a-disciplines of marketing and management.

The next point has to do with the distinction or otherwise between ideology and paradigm. Here Tribe argues for convergence, even to the extent that he claims that neo-liberalism can be considered to be both an ideology and a paradigm. However, if we accept the French literary distinction between describing persons as they are (Molière) and portraying people as they ought to be (Corneille) then evidently the former is paradigmatic and real while the latter is ideological and ideal. How then can neo-liberalism be a paradigm?

Finally, Tribe, while agreeing with several of my points confirming the Anglocentric character of many tourism studies, cannot bring himself to accept that it is linguistic hegemony that is the unjustifiable foundation for theoretical hegemony even to the point where Anglo-Saxon writers conveniently suffer from amnesia in failing to acknowledge true pioneers in the field who are thus airbrushed out of history on the pretext of English being the lingua franca of communication. Maybe I should have reinforced my argument by citing my corresponding analysis elsewhere of tourism researchers, tourism university courses, tourism associations and academies, and tourism publishing houses (Dann, 2011c).

By way of conclusion, initially it was decided to place this paper within a dialectical framework so that Jamal and Dann in offering alternatives (antitheses) to Tribe's theses would thereby open the door to various syntheses. In so doing it was hoped that our understanding of paradigms would advance. However, for one undeclared justification or another it was decided to abandon this Hegelian approach, maybe because it was deemed to be over-ambitious in the current context of at best only partial consensus in a preliminary study of this nature. Even so, and in spite of this apparent loss of framework necessary for the transition from paradigm lost 
to paradigm regained, this situation should not mark the end of our experimentation in trialogical presentation. Quite the contrary, it might encourage further similar attempts.

The reason for such optimism, as is often the case, may lie in the realisation that it has historical precedent. Indeed the present dialectical state-of-affairs may have its foundation in the Socratic "method" (Dann 2013), whereby knowledge progresses with the articulation and rejection of hypotheses and where wisdom is paradoxically identified with awareness of one's own ignorance (Socratic irony). In this regard Dann (2013) has further shown that the Socratic method of live debate in the agora of Athens lays the foundation for the scholastic proof adopted by Thomas Aquinas in which the very basis of learning is derived from the elimination of adversarial positions. Thus we are not that surprised when this doctor of the church and canonised saint initially asks in his Summa Theologica: 'Does God exist?" before promptly answering "It would seem not" However the strangeness of this rhetorical question and answer evaporates once the opponents' points of view have been demolished thereby opening the way for the articulation of the author's arguments. Indeed this scholastic approach to understanding is mirrored in the defence of doctoral theses by means of the classical disputation (Dann 1988) found in mediaeval universities and one or two institutions of higher learning today. The only real difference between such a practice and the Hegelian dialectic is that the former is typically conducted in Latin. Were we also to have adopted this approach that would have represented quite a challenge, discussing a live issue in a dead language. Maybe we should postpone such an exercise for another occasion. That like the current exercise would surely represent a first.

In the meantime we need to acknowledge that without the input of the late author of The Structure of Scientific Revolutions none of the foregoing debate would have taken place. It is therefore appropriate that we recognise his stimulus with the words: "God Save our Gracious Kuhn"

\section{REFERENCES}

ARAMBERRI, J. (2010). Modern Mass Tourism. Tourism Social Science Series. Vol 14. Bingley: Emerald.

ATELJEVIC, I., PRITCHARD, A., \& MORGAN, N. (2007). The critical turn in tourism studies: Innovative research methods. Oxford: Elsevier.

BAUMAN, Z. (2000). Liquid Modernity. Cambridge: Polity. 
BEM, A., \& MORAIS, L. (2013). Innovations in the fields of directors and sociology: in search of new paradigm for development of tourism. Revista Iberoamericana de Turismo (RITUR), 3(1), 86-112.

BERNSTEIN, R. J. (1983). Beyond Objectivism and Relativism: Science, Hermeneutics, and Praxis. Philadelphia: University of Pennsylvania Press.

BIRD, A. (2013). "Thomas Kuhn". In The Stanford Encyclopedia of Philosophy (Fall 2013 Edition), Edward N. Zalta (ed.), URL = http://plato.stanford.edu/archives/fall2013/entries/thomas-kuhn/. Accessed February 15,2014

CLOKE, P., \& JOHNSTON, R. (2005). Deconstructing human geography's binaries. Spaces of Geographical Thought: Deconstructing Human Geography's Binaries, 1-21.

COHEN, E. (1974). Who is a tourist?: a conceptual clarification. The sociological review, 22(4), 527-555.

COHEN, E. (1979). A phenomenology of tourist experiences. Sociology, 13(2), 179-201.

DANN, G. (1988). Tourism, Peace and the Classical Disputation. In J. Jafari and L. D' Amore (eds.), Proceedings of a conference on tourism: A vital force for peace, (pp.25-33). Montréal: L. D’Amore and Associates.

DANN, G. (1996). The language of tourism: a sociolinguistic perspective. Wallingford: CAB International.

DANN, G. (1997). Paradigms in Tourism Research. Annals of Tourism Research, 24(2), 472474.

DANN, G. (2011a). Take Me to the Hilton: The Language of Tourism Paradigm. Folia Turistica 25 (1), Special Edition on the Master Classes: 23-40. [Polish version: ,Zabierz mnie do Hiltona": Paradymat Języka Turystyki 25(1): 23-42].

DANN, G. (2011b). Paradigms in Tourism Research Re-visited. Paper presented to the symposium on Paradigms in Tourism Theory, University of Troms $\varnothing$, Norway, 16-17 November.

DANN, G. (2011c). Anglophone Hegemony in Tourism Studies”. Enlightening Tourism: A Path-making Journal $1(1): 1-30$.

(http://www.uhu.es/publicaciones/ojs/index.php/et/issue/current), July.

DANN, G. (2012). Re-modelling a Changing Language of Tourism: From Monologue to Dialogue and Trialogue. Pasos 10 (4), 59-70 (www.pasosonline.org).

DANN, G. (2013) Probing the Historical Context of Research Probes. Tourism, Recreation, Research 38(1): 99-100. 
DANN, G., and E. COHEN (1991) Sociology and Tourism. Annals of Tourism Research 18, 155-169.

DANN, G. and G. LIEBMAN PARRINELLO (2009) The sociology of tourism: European origins and developments. Bingley (UK): Emerald.

DENZIN, N. (1986) Postmodern social theory. Sociological Theory 4(2),194-207.

DENZIN, N. (1989). The research act, $3^{\text {rd }}$ ed. Englewood Cliffs: Prentice-Hall.

DENZIN, N. and LINCOLN, Y. (eds.) (2005). The SAGE Handbook of Qualitative Resesarch. Thousand Oaks: SAGE.

DREDGE, D. and JAMAL, T. (2013). Mobilities on the Gold Coast, Australia: Implications for destination governance and sustainable tourism. Journal of Sustainable Tourism, 21(4): 557-579.

ECHTNER, C. and JAMAL, T. (1997). The Disciplinary Dilemmas of Tourism Studies. Annals of Tourism Research, 24(4), 868-883.

FEYERABEND, P. (1975) Against Method. London: New Left Books.

FLETCHER, J., FYALL, A., GILBERT, D., \& WANHILL, S. (2013). Tourism: principles and practice: Harlow: Pearson.

FORD, J. (1975) Paradigms and fairy tales: An introduction to the science of meanings, vol.1.London: Routledge and Kegan Paul.

FOUCAUlT, M. (1980). The Eye of Power. In C. Gordon (Ed.), Power / Knowledge. Hemel Hempstead: Harvester.

FRANKLIN, A. and CRANG, M. (2001). 'The Trouble with Tourism and Travel Theory?', Tourist Studies 1(1): 5-22

FRANKLIN, A. (2004). Tourism as an Ordering: Towards a New Ontology of Tourism. Tourist Studies, 4(3), 277-301.

GIBBONS, M., LIMOGES, C., NOWOTNY, H., SCHWARTZMAN, S., SCOTT, P., \& TROW, M. (1994). The new production of knowledge. London: Sage.

GUBA, E. ed. (1990). The paradigm dialog. London: Sage

HANNAM, K. (2009). The end of tourism? Nomadology and the mobilities paradigm. In J. Tribe (Ed.), Philospophical issues in tourism (pp. 55-70). Clevedon: Channel View.

HANNAM, K., \& KNOX, D. (2010). Understanding Tourism: A Critical Introduction: SAGE.

HANNAM, K., SHELLER, M., \& URRY, J. (2006). Editorial: Mobilities, Immobilities and Moorings. Mobilities, 1(1), 1-22. 
HARDING, S. (2003). How Standpoint Methodology Informs Philosophy of Social Science. In The Blackwell Guide to the Philosophy of the Social Sciences. Stephen P. Turner and Paul A. Roth (editors). Oxford: Blackwell Publishing (pp. 291-310).

HOLLINSHEAD, K. (2009). The worldmaking prodigy of tourism: The reach and power of tourism in the dynamics of change and transformation. Tourism Analysis, 14(1), 139152.

HOLliNSHEAD, K., ATELJEVIC, I., and N. ALI (2009) Worldmaking AgencyWorldmaking Authority: The Sovereign Constitutive Role of Tourism. Tourism Geographies $11,427-443$.

HUNTER, C. (1997). Sustainable tourism as an adaptive paradigm. Annals of Tourism Research, 24(4), 850-867.

HUGHES, J. \& SHARROCK, W. (1997). The Philosophy of Social Research. NY: Longman. JAFARI, J. (2003). Research and scholarship: the basis of tourism education. Journal of Tourism Studies, 14(1), 6-16.

JAFARI, J. (2005). Bridging Out, Nesting Afield: Powering a new platform Journal of Tourism Studies, 1-5.

JAMAL, T. and EVERETT, J. (2004). Resisting rationalization in the natural and academic lifeworld: Critical tourism research or hermeneutic charity? Current Issues in Tourism, 7(1): $1-19$.

JAMAL, T. and HOLLINSHEAD, K. (2001). Tourism and the Forbidden Zone: The Underserved Power of Qualitative Research. Tourism Management, 22: 63-82.

JOVIČIĆ, Ž (1972) Turizmologija (Tourismology). Collected papers. Beograd: Faculty of Geography, University of Belgrade.

KUHN, T. (1962). The structure of scientific revolutions. Chicago: University of Chicago Press.

KUHN, T. ([1962] 1996). The structure of scientific revolutions. Chicago: University of Chicago Press

KOURANY, J. A. (1998). Scientific knowledge: Basic issues in the philosophy of science. Belmont, CA: Wadsworth Publishing Company.

LAKATOS, I. (1970). Falsification and the Methodology of Scientifie Research Progrsmmes. In Philosophies of Social Science: the Classic and Contemporary Readings. Gerard Delanty and Piet Strydom (editors). Philadelphia: Open University Press. 
LAKATOS, I. (1975). Falsification and the methodology of scientific research programmes Can Theories be Refuted? (pp. 205-259): Springer.

LAKATOS, I., WORRALL, J., \& CURRIE, G. (1978). The methodology of scientific research programmes (Vol. 1): Cambridge university press Cambridge.

LANFANT, M-F. (2005) Tourisme International. Incursions dans les Théories du Tourisme et du Loisir: Moindre Jouissance et/ou Plus de Jouir (International Tourism. Entries into the Theories of Tourism and Leisure: Less Pleasure and/or Surplus Pleasure). Paper presented to the International Academy for the Study of Tourism, Beijing Hotel, Beijing, July (pages not numbered).

LATOUR, B. (1999). Pandora's hope: essays on the reality of science studies: Harvard University Press.

LEIPER, N. (1981). Towards a cohesive curriculum tourism: The case for a distinct discipline. Annals of tourism Research, 8(1), 69-84.

LEIPER, N. (2000). An emerging discipline. Annals of Tourism Research, 27(3), 805-809.

LI, X. R., \& PETRICK, J. F. (2008). Tourism marketing in an era of paradigm shift. Journal of Travel Research, 46(3), 235-244.

LUO, Y., \& DENG, J. (2008). The new environmental paradigm and nature-based tourism motivation. Journal of Travel Research, 46(4), 392-402.

LYOTARD, J (1979) (1984) The postmodern condition: A report on knowledge. Minneapolis: University of Minnesota Press.

MACCANNELL, D. (1976). The tourist: A new theory of the leisure class: Univ of California Press.

MILLS, C. (1959). The sociological imagination. New York: Grove Press.

PERNECKY, T. (2012) Constructionism: Critical Pointers for Tourism Studies. Annals of Tourism Research 39:1116-1137.

PERNECKY, T. (forthcoming) Paradigm, tourism. In J. Jafari and H. Xiao (eds) Encyclopedia of Tourism. New York: Springer.

POPPER, K. (1959). The Logic of Scientific Discovery. London: Hutchinson.

POPPER, K. (1963). Conjectures and reflections. London: Routledge and Kegan Paul.

RITZER, G. (1975). Sociology: A multi-paradigm science. Boston: Allyn and Unwin.

SHELDON, P. J., FESENMAIER, D. R., \& TRIBE, J. (2011). The tourism education futures initiative (TEFI): activating change in tourism education. Journal of Teaching in Travel \& Tourism, 11(1), 2-23. 
SMART, B. (1994). Sociology, globalisation and postmodernity: Comments on the "Sociology for One World"thesis. International Sociology 9(2), 149-159.

SMITH, V. L. (1977). Hosts and guests. The anthropology of tourism. Pennsylvania: University of Pennsylvania Press.

SMITH, L. T. 1999 Decolonizing methodologies: Research and Indigenous peoples. London: Zed Books

SWAIN, M. B. 2004 (Dis)embodied experience and power dynamics in tourism research. In Qualitative Research in Tourism: Ontologies, Epistemologies and Methodologies, J. Phillimore and L. Goodson eds., pp. 102-118. London and NY: Routledge.

TRIBE, J. (1997). The indiscipline of tourism. Annals of Tourism Research, 24(3), 638-657.

TRIBE, J. (2000). Indisciplined and unsubstantiated. Annals of Tourism Research, 27(3), 809813.

TRIBE, J. (2006). The truth about tourism. Annals of Tourism Research, 33(2), 360-381.

TRIBE, J. (2010). Tribes, territories and networks in the tourism academy. Annals of Tourism Research, 37(1), 7-33.

TURNER, S. P. and ROTH, P.A. (2003). Introduction. Gosts and the Machine: Issues of Agency, Rationality, and Scientific Methodology in Contemporary Philosophy of Social Scence. In The Blackwell Guide to the Philosophy of the Social Sciences. Stephen P. Turner and Paul A. Roth (eds). Oxford: Blackwell Publishing (pp. 1-18).

URRY, J. (1990). The Tourist Gaze: Leisure and travel in contemporary societies: London: Sage.

URRY, J. (2000). Sociology beyond societies: Mobilities for the twenty-first century. London: Routledge.

VEIJOLA, S., \& JOKINEN, E. (1994). The Body in Tourism. Theory and Society, 11, 125151.

WEAVER, D. (2007). Towards sustainable mass tourism: Paradigm shift or paradigm nudge? Tourism Recreation Research, 32(3), 65-69.

WINCH, P. (1990). The Idea of a Social Science. London: Routledge and Kegan Paul.

XIAO, H., JAFARI, J., CLOKE, P., \& TRIBE, J. (2012). Annals: 40-40 vision. Annals of Tourism Research, 40, 352-385. 
